\title{
O profissionalismo e a construção do gênero na advocacia paulista
}

\author{
Maria da Gloria Bonelli \\ Doutora em Ciências Sociais \\ Professora do Departamento de Sociologia da UFSCar \\ gbonelli@uol.com.br \\ Rennê Martins Barbalho \\ Mestre em Sociologia - UFSCar \\ rennemartins@yahoo.com.br
}

\begin{abstract}
Resumo
Este artigo focaliza a construção social do gênero na advocacia, ambiente no qual o profissionalismo predomina. Baseia-se em levantamento quantitativo sobre as equipes dos escritórios de advocacia da cidade de São Paulo, e prioriza entrevistas qualitativas com 16 advogadas e advogados do interior e da capital desse estado. O argumento é que a ideologia do profissionalismo é parte constitutiva do processo de construção do gênero no trabalho profissional, alimentando distinções entre o feminino e masculino nos escritórios, em vez da superação dessas desigualdades ao viabilizar a profissionalização da advogada. O material mostra como esse processo é legitimado na carreira, tanto por homens quanto por mulheres. No entanto, as formas como essa construção ocorre diferenciam-se tanto pela posição alcançada na carreira, como pela origem social, geração e dupla jornada.
\end{abstract}

Palavras-chave: profissionalismo; advocacia; gênero; carreira jurídica.

\section{Introdução}

CRIAÇão DOS CURSOS JURídicos No BRASIL ocorre na primeira me-
tade do século XIX. Estes espaços públicos mantêm-se reservados
somente aos homens por várias décadas, período no qual se constituiu
o profissionalismo e o desenvolvimento da ideologia da neutralidade
como basilar à expertise. Os trabalhos acadêmicos sobre a origem e or-
ganização das profissões jurídicas não registram a presença de nenhuma
mulher (entre eles Adorno, 1988; Bonelli, 2002; Coelho, 1999). Perrot
(2005) nomeou as ausências não registradas nas análises históricas de os
silêncios da história.
A participação das mulheres nos cursos jurídicos ganha densidade a
partir da década de 1970, intensificando-se com o boom das faculdades
privadas de Direito nos anos 1990, que ampliou as oportunidades de
ingresso para aqueles provenientes de origens sociais diversificadas. En-
tretanto, os efeitos de uma ordem criadora articulada predominantemen-
te por homens, brancos, heterossexuais e da elite dominante durante o
primeiro século de existência dos cursos de Direito reforçam os traços de
desigualdades que ecoam na contemporaneidade, pois é um passado que
marca profundamente o presente profissional, entre homens e mulheres.
Partindo desse legado, hoje se observa o acentuado crescimento
da presença feminina na advocacia brasileira. Em 1996, havia $67 \%$ de 
homens registrados e 37\% de mulheres registradas na OAB nacional. Dez anos depois esta proporção atingiu 56\% a 44\%. Em São Paulo, em 2006, havia 116.948 homens e 93.245 mulheres na OAB (SP). O número de novas inscritas chegava a $52 \%$ superando os $48 \%$ deles, confirmando o processo em curso de feminização da atividade.

Acompanhando a mudança na composição de gênero da carreira registram-se também transformações na forma de organização do trabalho profissional, com a expansão das Sociedades de Advogados, grandes escritórios de advocacia controlados por sócios, que contratam associados para o desempenho do trabalho demandado por clientes empresariais. A prática liberal tradicional do tipo solo ou em escritórios de pequeno porte, voltados especialmente a clientes individuais, tem que lidar com essa nova realidade, que passa a ser a referência predominante no mercado profissional. A passagem de uma forma de organização para a outra foi facilitada pelo forte ingresso de mulheres na advocacia e sua inserção na posição de associada.

O expressivo crescimento na participação feminina entre os jovens profissionais, concomitante à conquista de direitos por parte das mulheres, alimenta a percepção de que as oportunidades se equilibraram entre homens e mulheres na advocacia. Com isso, o cenário das diferenças no mundo profissional do direito no século XXI não seria o da discriminação de gênero ${ }^{1}$, mas o da igualdade baseada no mérito, na dedicação e na competência. Várias profissionais bem-sucedidas nas grandes bancas afirmam essa mudança, entendendo que as carreiras que elas fizeram são evidências disso.

Esse artigo aborda como a precedência da masculinidade na conformação do mundo profissional jurídico permeia a ideologia do profissionalismo, baseada na neutralidade afetiva, na dedicação integral e na competência para prestar um serviço especializado de qualidade. Dessa forma, engendra a construção do masculino e do feminino no cotidiano profissional, ao designar as posições para aqueles que preenchem o modelo ideal plenamente e os que dele se distanciam de alguma forma. Os que são suspeitos de não virem a se dedicar totalmente à carreira (cuidados com a família), ou aqueles que corporificam uma imagem de si percebida como a antítese do neutro (a sexualidade visível, a emotividade, a politização, o trajar diferente do 'terno-terninho') perdem a pressuposição de sua competência, atestada pelo mérito da proveniência do diploma, da credencial da OAB e do currículo.

Segundo Feuvre e Lapeyere (2005), a construção do gênero na advocacia constituiu um 'script sexuado' de progressão na carreira, o qual pressupõe que os homens são competentes na esfera profissional não precisando demonstrar isso de antemão, ao passo que as mulheres precisam provar que são capazes. Há também o pressuposto que elas não têm disponibilidade total para o trabalho, atribuindo-se apenas às mulheres a conciliação da vida familiar e profissional. Os homens ficam dispensados dessa conciliação constituindo o perfil desejado pelas firmas de dedicação integral à profissão.

Essa construção das diferenças de gênero na advocacia foi observada em estudos internacionais, embora à proporção de participação feminina na carreira varie bastante segundo características nacionais. Países como o Japão e a Coréia do Sul apresentam baixa incidência de mulheres na advocacia, com menos de 10\%; França e a Finlândia já apresentam proporções um pouco superiores às do Brasil, chegando à metade do contingente. Numa posição intermediária encontram-se Estados Unidos e a Alemanha, em torno de 30\% (Schultz; Shaw, 2003).

A base de dados no qual esse artigo se apóia é constituída de dois tipos de fonte ${ }^{2}$ : informações coletadas no site do Centro de Estudos das Sociedades de Advogados (CESA), caracterizando os profissionais de 50 escritórios localizados na cidade de São Paulo filiados ao CESA, e entrevistas qualitativas com 13 advogadas e 3 advogados do interior e da capital desse Estado. O trabalho de campo foi feito em 2006 e 2007.

\section{A construção do gênero e do 'script sexuado' através do profissionalismo na advocacia}

A vigorosa inserção da mulher no mercado de trabalho jurídico é perpassada pela ideologia do profissionalismo engendrada nos significados simbólicos que constroem práticas diferentes para o masculino e o feminino. Disso resulta a estratificação da advocacia com carreiras marcadas pelo 'script sexuado'. Assim, observa-se a distribuição desigual dos advogados e das advogadas quanto à posição ocupada como sócio(a) ou associado(a), quanto ao tamanho do escritório em que atuam (pequeno, médio ou de grande porte) e quanto a clientela que representam prioritariamente (individual ou empresarial).

Para Freidson (2001), o que marca profundamente a distinção do profissionalismo para as demais formas de organização do trabalho é o caráter ideológico

10 gênero é concebido como uma construção cultural e social. É uma categoria analítica que questiona a naturalização da dualidade sexual como constitutiva da essência fixa e imutável do ser. Para uma síntese das mudanças no conceito de gênero e a introdução de uma nova utilização para a categoria mulher, ver Piscitelli (2002).

2 Em artigo publicado na revista Tempo Social, v. 20, n. 1, 2008, priorizamos a análise dos dados quantitativos reunidos em pesquisa sobre profissionalização e gênero nos escritórios de advocacia de São Paulo. Baseia-se, entre outras fontes, em um survey realizado com 216 jovens advogados (as). 
Tabela 1: Distribuição dos Advogados e Advogadas de Escritórios de Advocacia Filiados ao Cesa, Segundo o Tamanho do Escritório e a Posição Ocupada

\begin{tabular}{|l|l|l|l|l|l|l|}
\hline & \multicolumn{4}{|l|}{ SOCIOS } & \multicolumn{2}{l|}{ ASSOCIADOS } \\
\cline { 2 - 7 } & Homens & Mulheres & Total & Homens & Mulheres & Total \\
\hline Sociedades 1 a 9 Advogados & $71,1 \%$ & $28,9 \%$ & 45 & $61,7 \%$ & $38,3 \%$ & 47 \\
\hline Sociedades 10 a 49 Advogados & $71,2 \%$ & $28,8 \%$ & 125 & $46,6 \%$ & $53,4 \%$ & 451 \\
\hline Sociedades 50 Advogados ou mais & $76,5 \%$ & $23,5 \%$ & 371 & $52,2 \%$ & $47,8 \%$ & 1562 \\
\hline
\end{tabular}

Fonte: www.cesa.org.br

assentado no ideário da neutralidade. A importância do profissionalismo pode ser apreendida nas maneiras pelas quais os operadores do Direito, subjetivamente, avaliam suas experiências e percebem o significado de sua atuação. As formas de apreender as relações que envolvem as profissões e gênero são diferenciadas entre as carreiras e seus níveis hierárquicos, pela origem social, a geração e a dupla jornada. É necessário afirmar que as profissões, em especial as jurídicas, são marcadas pelas lutas concorrenciais nas quais os experts buscam deter o direito de dizer o que é direito em sua área de saber, sendo seguidos pelos leigos e a sociedade em geral.

A ideologia da neutralidade contrasta com a organização das sociedades de advogados. Em um levantamento feito no site do $\mathrm{Cesa}^{3}$, abarcando $20 \%$ dos escritórios filiados da cidade de São Paulo, foram selecionadas 50 sociedades de advogados, cujo quadro profissional totalizou 2.601 advogados(as). A Tabela 1 apresenta a distribuição dessa amostra, segundo o tamanho do escritório, a posição ocupada e o gênero.

Os advogados sócios são $75 \%$ e as advogadas sócias, 25\%; os advogados associados são $51 \%$ e as advogadas associadas, 49\% ${ }^{4}$. Quando essas sociedades são classificadas por faixas, conforme o número de advogados(as), registra-se uma barreira em todas as faixas para o ingresso de mulheres na condição de sócias. Os escritórios de médio porte, reunindo de 10 e 49 profissionais, apresentam maior participação de associadas (53\%), mas como sócias, as advogadas são $29 \%$. O ambiente menos receptivo é o modelo tradicional de escritório solo ou com poucos parceiros, em que os homens predominam com larga vantagem, como sócio (71\%) e associado (62\%), seguido das grandes sociedades de advogados (a partir de 50 profissionais), com $76 \%$ de sócios e $48 \%$ de associados.

A literatura específica refere-se à barreira de gênero que existe para o topo da profissão como 'teto de vidro' (glass ceiling). Junqueira (1999) reporta-se ao estudo de Thornton (1996) sobre as mulheres nas profissões jurídicas na Austrália, como também a estudos focalizando a mesma temática em outros países, para pensar as especificidades e as semelhanças com o caso brasileiro. O teto de vidro é comum a todos. Referese à barreira invisível que dá a ilusão de igualdade de oportunidades na carreira, mas bloqueia o acesso às posições elevadas da hierarquia profissional, mantendo as advogadas nas atividades menos valorizadas, que não preparam para posições de prestígio e poder, e têm pouco contato com clientes. Em países como os Estados Unidos, onde a inscrição da mulher na Ordem dos Advogados (Bar Association) só foi permitida a partir da década de 1970, alguns autores relacionam o teto de vidro com esse ingresso tardio, o que seria superado com o tempo. Entretanto, esse obstáculo existe nas mais variadas carreiras que incorporaram a participação feminina, bem como em diversos países de origens e tradições distintas. Esse bloqueio não pode ser superado apenas pelo tempo, sem mudanças na distribuição desigual de poder profissional e nas relações entre homens e mulheres no âmbito da casa.

A forma de construção do gênero na advocacia é imbricada à ideologia do profissionalismo, mas ela se diferencia em decorrência da posição ocupada na carreira, da origem social, da geração, dos cuidados com a família. O comum é que quando o gênero é visível, ele posiciona as advogadas nos lugares menos valorizados da carreira. Se ele é ocultado por meio dos discursos que enfatizam a competência como neutra e a igualdade de oportunidades, essa prática auxilia a ultrapassar as barreiras desse mercado profissional, mas reproduz a visão masculina nele.

Elida (53 anos) é uma advogada empresarial, atuante na área contratual. É natural do interior de Rondônia, onde seu pai tinha um cinema e sua mãe o ajudava. Como seus irmãos, ela saiu pra estudar em Manaus no secundário e o curso superior em São Paulo. Formou-se pelo Mackenzie, em 1974, é solteira. É sócia, junto a outros 52 advogados de um grande escritório paulista, que conta com 16 mulheres nessa posição. Comentando as diferenças que ela crê ter en-

3 Os grandes escritórios de advocacia se organizaram através da criação do Centro de Estudo das Sociedades de Advogados (Cesa). A sociedade de advogado baseia-se no modelo americano de estruturar a banca de advocacia, com uma administração profissional. Em geral, ela estratifica os advogados (as) em sócios (as) e associados (as). Os (as) sócios (as) comandam e controlam a participação no escritório, selecionando advogados (as) para trabalharem em suas equipes, como associados (as) que recebem remuneração mensal pelo trabalho realizado.

4 Com o aumento no número de mulheres ingressando na $O A B$, a tendência é esta proporção se inverter em breve. 
frentado na sua época de início na carreira e hoje, ela enfatiza as barreiras que superou e que, em sua visão, deixaram de existir.

Nada é fácil né, principalmente por ser mulher. Dificulta. Hoje eu acredito que não é mais tão aberta essa discriminação, por ser mais velada talvez seja até mais complicada. Porque antes, mesmo no trânsito, era "dona Maria vai para cozinha", hoje a coisa é mais discreta. Nesse sentido, na época da faculdade a preferência no estágio era dada para homens porque você tem que viajar, enfrentar o balcão no fórum, enfrentar o sexo oposto no balcão, por aí, então isso dificultava, hoje esse tipo de coisa que eu enfrentei não existe mais. Aqui mesmo no escritório, por exemplo, quando você acha um bom profissional para nós pouco importa que seja homem ou mulher, se é um talento, se é excelente vai ser contratado. Lógico dependendo você tem mais entrosamento em trabalhar com homem ou com mulher, depende. Eu acho até mulher no topo trabalhando com homem depende dela, ela talvez tenha até mais dificuldade porque os homens ligeiramente abaixo sentem-se mais insatisfeitos, uma situação um pouco delicada. Eu não tenho isso, trabalho perfeitamente com homem ou com mulher. Eu sou sócia do escritório, cada sócio tem a sua equipe e você administra aquela equipe (Elida).

Entretanto, a neutralidade da expertise vai cedendo lugar à construção do gênero na advocacia, conforme Elida relata as diferenças que vê entre masculino e feminino.

[...] No meu caso eu acho até que não tive problemas, porque eu não tenho filhos e não sou casada, então é mais tranqüilo porque a minha vida toda foi muito dedicada ao trabalho. [...] Não foi só uma opção pelo trabalho, foi uma opção de vida. Foi uma escolha minha, eu acho que o trabalho não interferiu em nada disso. Eu poderia ter casado e continuado a trabalhar como a maioria das sócias do escritório. É o exemplo da C (diretora de RH que estava presente na entrevista) que tem dois filhos, eu sei que é difícil para a mulher porque ela tem que se dividir, mas a mulher consegue fazer isso, nisso ela tem uma diferença do homem, ela consegue fazer várias coisas ao mesmo tempo, de pensar em coisas diferentes ao mesmo tempo. Ela tem sim que achar um equilíbrio, não tenho a menor dúvida, acho que essa é a grande dificuldade da mulher executiva hoje, seja na carreira jurídica ou qualquer outra carreira, é ter esse equilíbrio. Agora a diferença entre homem e mulher, quem tem a maior capacidade, isso é bobagem, eu acho que os dois têm qualificações e competências diferentes, e eu acho que eles têm de somar, complementar, um complementa o outro, um é bom numa coisa e o outro em outra, então os dois juntos se complementam, eu acho que tem que desenvolver como construir, porque é importante que você tenha as duas competências na empresa, porque a empresa sai ganhando. Porque a mulher, a maior capacidade dela é fazer diversas coisas ao mesmo tempo, os homens geralmente não conseguem, eles são focados numa coisa só, não é assim, mas um complementa o outro, porque eles são muito melhores em outras coisas que elas não são, então são competências diferentes, mas elas se complementam, tem que se complementar. (Elida).

A visão neutra que Elida apresenta sobre a carreira, não interferindo nas opções pessoais, não discriminando gênero e viabilizando independência a eles e a elas contrasta com sua fala sobre a dificuldade das mulheres em acharem um equilíbrio entre as jornadas da casa e do escritório. Decorrente do treino cotidiano no acúmulo de tarefas, as mulheres desenvolvem a capacidade de fazer diversas coisas ao mesmo tempo. A qualidade do feminino que é valorizada por Elida para compor a equipe da firma é resultante da dupla jornada de trabalho.

A neutralidade também aparece na forma de Esmeralda (45 anos) apresentar o escritório do qual é sócia. Ela formou-se pela Faculdade de Direito de Franca, atuando em Direito Tributário, área em que tem mestrado pela PUC (SP). Veio para São Paulo, em 1985, após ser aprovada em um concurso do Banco do Brasil, que lhe ajudou a financiar o mestrado. Ingressou no escritório em 1987 e tornou-se sócia em 1990. Casou, em 1991, com um sócio do mesmo escritório. É filha de um advogado bem-sucedido, que segundo ela, dedicou-se $90 \%$ do tempo à profissão e $10 \%$ à família. A mãe foi professora, em uma família com histórico das mulheres trabalharem. Quando jovem tinha resistência a ser advogada graças às longas jornadas de trabalho de seu pai. Tendo uma filha de 9 anos e uma de 13 anos, ela trabalha diariamente de 10 a 12 horas no escritório.

Segundo ela:

Eu tive logo uma progressão boa na minha carreira. E também não tinha[...] não era casada. Era uma pessoa completamente dedicada à profissão. Então, nos três primeiros anos, eu trabalhava muito. Quer dizer, ainda trabalho. Mas eu tinha total dedicação ao escritório e isso faz diferença [...]. Tenho muito prazer por ser advogada. É uma felicidade muito grande, eu sempre digo gostar da segunda-feira. Eu sempre disse que eu só seria feliz numa profissão o dia que eu gostasse da segunda-feira. As minhas irmãs brincam comigo e dizem que também gostam da profissão, mas dizem que detestam a segunda-feira. Que a esse nível! [...]. Esse tipo de advocacia que a gente faz aqui no escritório, eu acho que vale o comentário, é uma advocacia de empresa, de negócio, né[...]. A advocacia que a gente faz é [...] altamente profissionalizada, com um standard in- 
ternacionalizado: 70\% dos nossos clientes são empresas internacionais. É 50\% do seu tempo você tem que falar uma língua estrangeira. E [...] adota um parâmetro de profissionalização que são os parâmetros internacionais de prática da advocacia (Esmeralda).

Entretanto, ao referir-se à experiência cotidiana de trabalho com advogadas e advogados, participa da construção do gênero na advocacia, que ela também experimenta na vida privada dos cuidados com as filhas.

[...] Eu gosto muito de trabalhar com mulheres. Acho que são muito cuidadosas. Os homens também, ótimos advogados óbvio. Mas eu tenho gosto por trabalhar com mulheres porque elas têm uma característica que é mais comum nas mulheres do que nos homens, na minha opinião. Elas têm um cuidado maior. Nas questões que exigem uma atenção ao detalhe, à minúcia e eu acho as mulheres. [...]. E, não vejo assim uma diferença marcante entre um bom profissional e uma boa profissional. Mas por alguma razão há um número muito maior de homens do que de mulheres. Especialmente na minha área da advocacia. $\mathrm{Na}$ área, por exemplo, de família aqui no escritório que a sócia também é uma sócia mulher, ela só trabalha com mulheres $[\ldots]$. Eu tenho dito muito para essa outra sócia que trabalha comigo no nosso departamento. Que eu me dou muito bem. Nós temos muitas conversas íntimas e esse é um aspecto que eu sempre trato com ela. E ela é casada, casada com um juiz e ela tem duas filhas, duas filhinhas gêmeas. E tudo bem, vai levando a vida dela, mas [...] nessa luta de aproveitamento do tempo. E eu sempre digo pra ela: [...] nós temos que ser capazes de indicar para as advogadas que trabalham aqui que, ao trabalhar aqui, elas também podem ser felizes. Por que não é impossível uma mulher trabalhar aqui e [...] ter filhos, casar [...] Ela pode também optar por não ter sua família, mas é uma opção que ela faz. Se isso acontecer tudo bem. Mas ela não pode sentir que para trabalhar aqui ela tem que fazer esta... tomar essa decisão. Os dois não podem ser incompatíveis [...] aqui que é mais difícil mesmo [...] Eu não sei como você sobreviver num ambiente desses sem se dedicar ao profissional. Não tem esse negócio de oito horas (Esmeralda).

Para Esmeralda, o feminino aparece como cuidado. As advogadas são mais cuidadosas, como as mães. $\mathrm{O}$ universo privado da experiência cotidiana com a família é a marca que contrasta com a neutralidade do profissionalismo, com não ter diferença entre ser bom ou boa profissional. Embora afirme isso, sente que precisa provar para as jovens que a dedicação ao escritório não é incompatível com a vida familiar e a felicidade. A masculinização do ideário adiciona este custo, dar provas de que partilha de valores femininos, de que pode ser um exemplo para a sua equipe de advogadas não só no profissionalismo, mas também na esfera privada.

No mercado liberal da advocacia no Brasil, os escritórios de médio porte são os que mais contam com a participação de advogadas, mas elas ocupam posições assalariadas, desenvolvem atividades mais rotineiras, com menos imprevistos sobre o horário de trabalho. Na condição de sócia, as advogadas ocupam uma fatia menor dos lugares no conjunto dos escritórios, em torno de $25 \%$.

Ao contrário da visão neutra, a literatura especializada relaciona a concentração das advogadas nas posições menos valorizadas da carreira ao preconceito das firmas, que partem do estereótipo que as advogadas não têm disponibilidade para o grau de dedicação exigido e precisam provar sua competência - pré-julgamentos que não se aplicam aos advogados - como resultado de um 'script sexuado'. Nele, a conciliação da vida familiar e profissional é atribuição exclusivamente feminina e a pressuposição da competência na esfera profissional é monopolizada pelos homens (Feuvre; Lapeyere, 2005, p. 113). A indisponibilidade masculina na esfera doméstica combina-se com a escolha das mulheres por trabalhos que lhes permitam usufruir de soberania sobre seu tempo, e de exercê-lo em locais que lhes sejam menos hostis, o que explicaria em parte, a sub-representação do gênero feminino nas posições privilegiadas no mercado profissional, fator que incide sobre a remuneração obtida.

A combinação desses fatores intensifica a busca das mulheres por carreiras jurídicas mais estáveis, através de concursos públicos, alternativa que aparece para várias delas como a única saída.

Lucia (30 anos) formou-se pela Faculdade de Direito de Sorocaba em 1998. Atua na área de Direito Administrativo e é casada com um advogado. Seu pai é contador e sua mãe dona de casa. Sua fala revela as limitações no capital social para formar clientela, imprescindível no exercício liberal da advocacia.

A advocacia foi mesmo uma necessidade, quando me formei e tirei a carteirinha da Ordem fui trabalhar, mas tento concurso público desde quando me formei. Eu trabalho aqui em São Paulo para a municipalidade, sou analista jurídica, sou concursada. Hoje há uma presença muito forte das mulheres. Eu tenho a sensação de que as mulheres têm uma dedicação maior para estudo, para se aprofundar, então eu acho que elas acabam tendo até uma facilidade muito grande, você percebe muito isso em concurso público, onde os índices de aprovação das mulheres é maior. [...] Quando você advoga por conta própria a correria é muito maior, a busca de clientes é [...] buscar clientes mesmo e até a questão da instabilidade, é muito complicada esta questão. Eu acho mais difícil para a mulher, até outro dia eu estava falando com meu marido, eu acho que a mulher não agüenta muito a instabilidade da advocacia particular, de em um mês estar com dinheiro e no mês seguinte não entrar nada. 
Acho que até por isso as mulheres migram muito para concurso até porque de regra a mulher já estuda mais, é mais voltada para o estudo e não agüenta muito a instabilidade da advocacia. Está mudando um pouco, mas o homem tem mais o costume de sair mais, de ir mais à busca de clientes, se expõe mais; a mulher já é mais na dela, concentrada. Eu acho que a mulher é melhor para um serviço extremamente intelectual e não aquela coisa de ficar correndo atrás de cliente, o homem nesse ponto já é mais dinâmico para isso (Lucia).

Lucia tenta concurso público para a magistratura há vários anos. A partir dessa expectativa, ela construiu uma imagem contrastante das relações de gênero na advocacia e nas carreiras públicas. No Judiciário, o ambiente seria receptivo à igualdade, não havendo discriminação.

Eu não acredito muito nisso, penso que isso é reflexo do que acontecia no passado. Você pode perceber que a faixa etária dos tribunais é mais alta e nessa época não entrava mulher, então eu imagino que daqui uns 20 ou 25 anos isso mude, o ingresso das mulheres hoje nos quadros da magistratura ou do ministério publico é bem maior, então eu acho que vai acontecer uma inversão lá prá frente. Hoje você já consegue ver mulheres indicadas para Tribunais Regionais. Então, essa situação de hoje ter poucas mulheres é um reflexo do passado mesmo, onde você tinha poucas mulheres fazendo faculdade de Direito e poucas ingressando em Tribunais, eu acho que isso é um reflexo (Lucia).

A essencialização do feminino e do masculino também aparece nessa entrevista, mas a construção do gênero ganha um novo molde. A conduta profissional não discrimina, mas ela não existe mais na advocacia, e sim nas posições autônomas das carreiras do Ministério Público e da Magistratura. A advocacia é um terreno para homens, para quem estuda menos. A expertise cede lugar à sujeição a regras da concorrência no mercado. As mulheres estariam em busca de ambientes em que predomina o profissionalismo e a neutralidade. Essa visão da ausência de discriminação na ascensão nas carreiras públicas não se confirma na realidade. O tempo não é suficiente para dissolver o teto de vidro, que atua diferenciado o número de juízes e de juízas que alcançam a segunda instância e os tribunais superiores.

Ornela (34 anos) dedica-se a estudar para concursos da magistratura. Formou-se primeiro em Comunicação, na USP. Atuou vários anos nessa área, mas também fez três anos do curso de graduação em História. Ela decidiu cursar Direito, que concluiu em 2005, na PUC(SP), visando a carreira de juíza. A prática da advocacia é apenas para preencher o requisito de três anos de experiência, que é exigido para o concurso. Ela é casada com um publicitário, e não tem filhos. Seu pai é economista e sua mãe professora de inglês. A visão que apresenta da advocacia espelha os obstáculos atuais nessa profissionalização.

Muito difícil para a mulher e para todos em geral, primeiro porque o mercado está superinflado e a justiça é lenta exatamente por causa disso. É muito difícil ser um advogado autônomo, que trabalha sozinho. Tem muitos elementos que complicam; se a mulher é autônoma e fica grávida como ela faz? Ela vai ter que se virar de algum jeito; para o homem nesse sentido é mais fácil, ele não tem esse problema. Se a mulher tem filhos e é autônoma ela vai ter uma carreira muito atribulada e mesmo se trabalhar num escritório grande a exigência é muito grande.

(A advocacia) é lutar. Lutar contra tudo e contra todos. Primeiro contra a morosidade da justiça, segundo contra o cliente que nunca quer te pagar. Nunca né, para você receber é um horror. Trabalhar sozinha é bem mais difícil porque você não tem suporte nenhum. Você arruma um cliente e depois ele não te paga então é bem difícil, eu jamais advogaria. Eu sei que a carreira da magistratura é bem difícil, mas mesmo assim eu acho que para a mulher é melhor. O advogado é profundamente desrespeitado, hoje é uma classe menosprezada. Eu optei pela magistratura porque é uma área que você tem que estar constantemente atualizada, você não pára [...] tem que estudar. Nesses anos que eu estou estudando tenho um grupo de amigos, nove já passaram e são nove mulheres, eles vão ficando para trás. [...] Na magistratura acho muito raro existir preconceito entre homem e mulher, pode ter no exame oral. É verdade que no exame oral a mulher tem que mostrar que sabe muito mais do que o homem. Eles testam o perfil psicológico da mulher numa capacidade muito mais intensa do que do homem, eu já assisti provas orais, ela é mais exigida, para avaliar como agiria numa audiência, para ver como ela se comportaria, por exemplo, ela estando numa cidade do interior ver como ela se comportaria, já teve perguntas assim: usaria biquíni se fosse a um clube? Iria em churrasco do prefeito da cidade? (Ornela).

Ornela e Lucia construíram uma visão semelhante sobre o profissionalismo e o gênero, no que se refere às diferenças entre a advocacia e as carreiras jurídicas concursadas. A mesma avaliação sobre as dificuldades e o desprestígio da advocacia é partilhada também por Evandro, mas ele encontra saída para o exercício profissional na advocacia empresarial. Ele identifica a existência de discriminação de gênero nas profissões jurídicas, em especial no Judiciário, e procura contrastar sua atuação, mostrando-se como um profissional sem esse preconceito. $\mathrm{Na}$ prática, ele reforça a construção do gênero na advocacia, mas o faz de forma distinta. As marcas do feminino e do masculino são acompanhadas das diferenças na hierarquia. As mulheres se adaptam melhor às atuais condições da 
profissão, que são negativas. Elas são sensíveis, tranqüilas, calmas, cuidadosas. Para ele, a advocacia vive um processo de estratificação e perda de prestígio e as mulheres se ajustam melhor a isso. $\mathrm{O}$ aumento da participação das mulheres na carreira é acompanhando da perda de status da advocacia.

Evandro tem 29 anos, é solteiro, formou-se em 1997, pela Faculdade de Direito de São Bernardo do Campo, e atua na área jurídica desde que ingressou na faculdade, em 1992. Seu pai é empresário e sua mãe dona de casa.

[...] Hoje ser advogado é lutar por uma causa nebulosa, porque a gente luta por justiça e a todo momento a gente não tem certeza se a justiça está sendo feita. $\mathrm{O}$ sinônimo de advogado é luta. Desprestígio por conta de uma organização incompetente, governamental também. A carreira está muito desprestigiada, por conta do Estado [...]. Hoje em dia a maioria dos advogados inscritos na Ordem são mulheres, salvo engano $52 \%$ ou $53 \%$ e a tendência é aumentar, porque as mulheres se adaptam melhor à profissão. Eu acho que elas são mais sensíveis, mais sensatas, mais tranqüilas e nossa profissão demanda muito isso, ainda mais nos dias de hoje que está tudo errado, nosso judiciário está capenga, falta funcionário, falta material, inclusive não só os advogados aqui dentro do fórum, as atendentes, os cartorários femininos são muito melhores, são mais calmos, acessíveis, é diferente, eu acho melhor [...] No escritório em que eu trabalho tem mais três advogadas e duas estagiárias, eu quem contratei e fiz questão que fossem mulher, porque são melhores. Eu sou o único homem. Na verdade eu sou gerente jurídico do escritório porque eu estou lá há muitos anos e fiz amizades, aí faz dois anos que estou nesse cargo, daí eu passei a contratar e opto por mulheres. Por causa dessas qualidades todas, eu acho que elas são mais tranqüilas. [...] São mais cuidadosas. A única coisa em que as mulheres saem perdendo são nessas coisas braçais, porque a gente tem que carregar processo. Era para vir uma colega de trabalho, eu não permito (Evandro).

Segundo Feuvre e Lapeyere (2005), o 'script sexuado' também segrega internamente as profissões jurídicas no que se refere à especialização e a oferta equilibrada de serviços jurídicos pelo território. Para as autoras, a sub-representação das mulheres no exercício profissional é preocupante porque as advogadas ultrapassarão o número de homens no exercício da advocacia, e

não representam mais do que uma pequena minoria de indivíduos eleitos para refletir sobre as transformações estruturais em curso e para elaborar as estratégias de defesa dos interesses da profissão no futuro. (Fevre; Lapeyere, 2005, p.122).

Vários são os fatores que beneficiam os advogados em detrimento das advogadas no processo de profis- sionalização. O capital social é o primeiro deles. Para Schultz e Shaw (2003), o capital acadêmico é partilhado por ambos os gêneros, mas a entrada na profissão e a progressão nela dependem do acesso a grupos hegemônicos de poder que atuam como mentores e notáveis. Como as mulheres estão menos posicionadas no topo da profissão, elas têm mais dificuldade de constituir essas redes. Além disso, chegar até a posição de sócio requer capital social para recrutar novos clientes empresariais e debitar mais horas de serviços prestados. O caminho até lá passa pela sociabilidade em práticas que consolidam vínculos de masculinidade, como formar times de futebol, sair para beber com os colegas, conversar sobre esportes, jantar com clientes, entre outras atividades que compõem o diferencial de gênero não acessível às advogadas. O capital social feminino também é escasso nas funções de representação nas associações profissionais, constituindo um perfil profissional mais desfavorecido desses atributos.

Sendo o impacto do gênero tão forte para estratificar a carreira, as mulheres que conseguem superar as barreiras de ingresso como sócias são aquelas que melhor realizam o apagamento do gênero, e o discurso sobre a conquista da igualdade de oportunidades é uma das formas de fazê-lo. Aceitar o 'desafio' de ter que provar ser tão capaz quanto os advogados é o outro lado da mesma moeda que alimenta as invisibilidades do gênero (Scott,1998).

As falas de Elida e de Esmeralda apresentadas acima configuram uma forma de apagar as marcas do gênero, e alcançar posições privilegiadas da carreira. Já a entrevista de Adelaide, a seguir, revelará outra forma de enfrentar esse desafio, em uma especialização que potencializa a essencialização da masculinidade, que é a advocacia criminal, no Tribunal do Júri, lidando com o crime e a violência.

Adelaide é uma advogada criminalista de 58 anos, com três filhas e divorciada. Faz parte da geração de mulheres que ingressou na faculdade após a maternidade, em meados da década de 1980, quando as duas primeiras filhas já tinham 14 e 15 anos. O período da faculdade foi marcado pela terceira gravidez, no primeiro ano, e por problemas de saúde decorrentes dela, que resultou em uma interrupção temporária dos estudos, e pela separação, no quinto ano. Formou-se em 1989, pela FMU. É proveniente de uma família de baixa escolaridade. Sua mãe estudou até o quarto ano primário e seu pai fez apenas o primeiro. Como autodidata, ele chegou a vice-presidente da primeira fábrica de cigarros com filtro no Brasil. Foi convidada para ser assistente de um criminalista e passou a atuar no Tribunal do Júri, como advogada de defesa, em 1991. Na gestão de D'Urso à frente da OAB(SP), envolveuse com a Comissão da Mulher Advogada.

Para ela, ser uma mulher no Tribunal de Júri:

É uma fissura. Toda aquela sagacidade da mulher, toda 
aquela coisa que a gente tem instintiva, você sabe onde você tem que estar vocacionada. [...] São poucas mulheres que atuam no júri. O grande problema é que dá um temor, porque você fica numa posição, você é uma grande vidraça, porque a polícia faz a prova acusatória, o promotor vem com a segunda carga, a sociedade dependendo dos casos que você assume, ela vem com tudo em cima da defesa. Porque acha que o advogado vai colocar todo mundo na rua, e não é assim. [...] É um desafio muito grande, eu não posso falar nada porque eu sou apaixonadíssima. A fissura maior do júri é você desafiar, é muitas vezes o indefensável. Muitas vezes é uma frase de uma testemunha e você pensa eu vou partir para essa defesa. [...]Nós já temos quatro jornadas né. Outra coisa é não perder a feminilidade na atuação, tanto como advogada como no plenário, não ficar usando jargões pesados, usar as palavrinhas mágicas "por favor", mesmo na hora do "aparte" falar "desculpe" o senhor não está cumprindo sua obrigação, ou seja lá o que for. [...] Você tem que ser um polvo realmente, eu gosto de desafio, e você tem que aprender a trabalhar, você pega o processo no inquérito e desenvolve em todas as áreas, então você aplica até sociologia, o papel do réu, então é uma situação assim de você saber trabalhar, se tiver a mídia você tem que saber lidar com ela, observar o código de ética, a mulher é muito visada em determinados tipos que ela pega de cliente [...]. Na minha área a mulher advogada tem que se postar, tem que usar o charme que a mulher tem, trajar-se bem vestida, portar-se com elegância, não usar jargões baixos, não ser uma mulher sem classe, ela pode ser contundente, combativa, eu me ponho. $\mathrm{Na}$ hora em que visto a beca, eu me transformo efetivamente, porque lá estou com a minha tarja vermelha no meu braço esquerdo, significa que é defesa, eu adoro ser defesa, eu sou apaixonada pela minha profissão, eu gosto de desafios. A prova é hoje estar aqui na Comissão da Mulher Advogada (Adelaide).

O depoimento de Adelaide ilustra as ambigüidades da construção do gênero em uma especialização jurídica cuja expertise não consegue ser neutra a ponto de dar invisibilidade à violência que chega até o julgamento, e a baixa estima social dos réus. Em um ambiente hostil, a profissionalização e o sucesso de Adelaide resultaram de uma ênfase nas habilidades femininas que preservam a deferência à autoridade masculina dos profissionais da justiça. As características de sua trajetória precedente ao ingresso na carreira, voltadas aos cuidados com a família e ao magistério, foram incorporadas no cotidiano jurídico, mas as tentativas discursivas de realizar o apagamento dessas marcas, quando elas se consolidam como obstáculos, também se verificam.

Já sua relação com a profissão e com os operadores do Direito é apresentada na chave da vocação, da paixão, da igualdade na competência e na neutralidade do profissionalismo. Ela relaciona aos leigos (o júri, o público, à mídia) a conduta anti-profissional, preconceituosa, agressiva, tendenciosa, mas não aos colegas. Adelaide foi advogada dos proprietários da Escola de Base, presos acusados de abusar sexualmente de crianças na escola. Foi assistente de acusação do caso Bodega, e depois foi advogada de Francisco de Assis Pereira, o maníaco do parque.

[...] Foi um caso complicado, no tocante à formação das provas porque as testemunhas eram mulheres, mas a tese que era e que é até hoje é "sociopatia" [...] Infelizmente, perdi o júri [...]. E o nosso júri, por conseqüência de todo o processo, e todas as inverdades, as agressões, as ameaças de morte que eu sofri, que eu era canalha, cafajeste, que eu não tinha filha, era um caos. As minhas filhas saíram brigando com todo mundo, a minha pequena, na época, estudava no Liceu Pasteur Brasileiro, ela bateu numa criança, porque xingaram aquela loira de filha daquilo, e então ela se ofendeu e bateu, porque a mãe era advogada do maníaco do parque. Em conseqüência disso eu tive que me afastar da minha família para preservá-la e tive que colocar segurança para meus pais, que foram ameaçados de morte, e eu não desisti porque o único lugar que eu tinha para falar tudo o que eu pensava da hipócrita sociedade, da mídia que não vale nada em determinados casos que imputam e depois não sabe comprovar e aí eu fui mencionar todo o histórico da minha vida. E aí eu tive um câncer emocional, porque eu fui execrada, eu apanhei na rua, eu tomei umas três surras na rua. Então todo mundo dizia desiste, desiste, eu falei: não vou desistir. [...] Tem determinadas emissoras que, se eu pegar um caso e ela souber, ela me retalia de cara.

[...] Eu vou dizer uma coisa para você, eu tenho 58 anos, eu sou avó, sou mãe, sou filha, sou tia e sou advogada, e olha de casos que me geraram uma encrenca hein. Eu nunca fui discriminada, eu nunca fui discriminada, por colega, por juiz, por promotor, ao contrário, eu tenho um relacionamento excelente. Então isso é que é gostoso, eu nunca sofri uma discriminação, com tudo que eu possa ter sofrido de coisa, eu não sofri discriminação nem de juiz, promotor nem dos meus colegas (Adelaide).

As mesmas ambivalências aparecem na sua visão sobre a atuação da Comissão da Mulher Advogada e sobre o feminismo.

Porque no feminismo você quer, como é que você quer ser feminista no eu, eu, eu. E o nós, onde fica? O movimento feminista não aceita a parceria com os homens, ele é excludente. É um movimento só de mulheres, mulheres, mulheres. E o princípio do Direito que todos nós somos iguais perante a lei? No inicio da minha comissão aconteceu um fato pitoresco porque uma delas, não está mais comigo, eu cheguei nessa gestão, venho da época da eleição do D’Urso, e falei: é um bando de generais, porque eu as conheço há mais de vinte anos, e numa 
reunião ela disse "homem aqui não entra!” E, nossa, me deu um piti e eu falei: mas como não entra? Espera um pouco minha cara, aqui vai entrar todos. Gente você tem que somar, não podemos ser radical em tudo. Por que eu tenho que ser xiita nisso? Porque sou mulher? Não estou discutindo opção sexual, raça, credo; eu estou discutindo eu, mulher. Você tem direito de discutir o aborto se você é favorável ou contra. Eu sou a favor? Então tá bom eu vou começar a contestar toda a lei que é furada, já começa pelo atestado de óbito que é dado errado, eles vão pela parada dos batimentos cardíacos, mas a lei manda pelas vibrações do cérebro, então estão todos nulos esses atestados de óbitos, então vamos modificar. Eu acho que você pode reivindicar todo o seu posicionamento, sem se tornar amarga (Adelaide).

O gênero é construído na prática da advocacia reforçando a subalternidade feminina mediante comportamentos dóceis, das formas adequadas de se vestir e portar. No entanto, o gênero, tão visível no depoimento ao referir-se a esses aspectos, precisa tornarse invisível quando se trata de uma advogada criminalista bem-sucedida diante de seus pares, em uma especialização que é vista como típica de advogado. A operação dessa passagem não se dá como mágica. Ela requer trabalho emocional (Hochschild, 2003), e a administração de sentimentos que estão sem sintonia entre o que a pessoa sente e o que espera sentir em relação à experiência na profissão. O discurso da negação da discriminação é uma forma de se tentar alcançar a igualdade de oportunidade, e é acentuado entre as profissionais que ultrapassaram várias das barreiras à ascensão profissional.

O profissionalismo concebido no final do século XIX e início do século XX, contexto que reservava a rua, o público e a expertise para os homens - a casa, o privado e o leigo para as mulheres - incorpora as advogadas divididas pela forma como lidam com o gênero. Aquelas que conseguem superar os obstáculos para tornar-se sócia são também as bem-sucedidas na realização do trabalho ideológico e de administração das emoções ${ }^{5}$ para se ajustarem aos valores masculinos da profissão. A igualdade de oportunidades só parece alcançável operada a masculinização do ideário e da prática profissional.

\section{Conclusão}

As diferenças culturais e sociais entre masculino e feminino são construídas no cotidiano dos escritórios de advocacia, traduzindo os significados da essencialização do gênero para o mundo profissional do Direito. Homens e mulheres participam dessa empreitada, que é marcada pela posição ocupada na estratificação da carreira, pela origem social, pela geração e pela dupla jornada.

A maternidade é o aspecto principal para marcar o gênero feminino, em confronto com os conteúdos do profissionalismo nas Sociedades de Advogados. Como o aspecto central é o da dedicação exclusiva, que requer muitas horas de trabalho acima da jornada regular, e o da neutralidade em relação ao comportamento afetivo que privilegia os cuidados com a família, essa concepção de profissionalismo impõe barreiras às mulheres. Esse pressuposto se antecipa às escolhas das advogadas, reduzindo o interesse dos escritórios em investir profissionalmente nelas, reforçando o teto de vidro ao manter as mulheres em posições subalternas dentro da carreira. Estas são marcadas pelas atividades rotineiras, de baixa especialização, faz-tudo, mas com maior controle sobre o tempo e a vida pessoal (os cuidados). Nesse contexto, elas priorizam os ambientes menos hostis, cujas tarefas sofrem menos imprevistos reduzindo o tempo livre.

Para ultrapassar a barreira e o estereótipo que se atribui às advogadas, recorre-se à masculinização do ideário e da prática, adotando o mesmo sentido de profissionalismo, associado às jornadas de trabalho superiores a 12 horas diárias, realizando o apagamento do gênero, com a ideologia da neutralidade que não distingue homem de mulher na competência profissional. Essas falas das advogadas bem-sucedidas ajudam a criar oportunidades, que são aproveitadas na superação de obstáculos à carreira e ao reconhecimento de sua expertise.

As advogadas entrevistadas que alcançaram o sucesso profissional se deparam com o custo emocional de lidarem com essa masculinização. Ela envolve a formulação de argumentos e de sentimentos sobre a menor atenção aos cuidados com os filhos, e o temor do que isso poderá representar no futuro deles. Envolve também a forma como a masculinização é percebida pelos pares, homens e mulheres, que as associam a uma vida pessoal infeliz, questionando a legitimidade dessa estratégia. Elas precisam provar aos colegas, e em especial às jovens profissionais, que tal caminho leva à realização pessoal.

A valorização da autonomia sobre o próprio tempo tem crescido no mundo profissional, com o aumento da participação das mulheres nas carreiras e tem influenciado os homens. Ter algum controle sobre seu tempo significa, para uns, melhor qualidade de vida, para outros, dedicação à família. Este é um impacto relevante das mulheres sobre o profissionalismo concebido de forma tradicional, o que preocupa as empresas e as sociedades de advogados na sua reprodução do capital humano, pois

5 Arlie Hochschild (2003) conceituou o trabalho emocional como a forma consciente como as pessoas atuam para suprimir a distância entre o que estão sentindo e o ideal que têm do que deveriam sentir, com a submissão dos sentimentos à manipulação e a serem administrados, muitas vezes assumindo a característica de uma jornada de trabalho extra. A inconsistência de sentimentos entre o eu profundo e eu na superfície se revela muitas vezes, através da ironia, do sarcasmo. Os subalternos realizam mais trabalho emocional que os dominantes, assim, as mulheres fazem mais que os homens. Ver Bonelli (2004). 
sinaliza a perda de pessoal competente para as carreiras jurídicas do setor público. Eles também estão valorizando ambientes de trabalho menos hostis quanto à dedicação full time, seja por motivo de saúde, seja por ter tido vários casamentos desfeitos, para ficar mais perto dos filhos ou ter uma melhor qualidade de vida.

O profissionalismo se apresenta como um modelo de organização do trabalho em que as invisibilidades são alimentadas e mantidas pelo discurso da ideologia da neutralidade. Ao mesmo tempo, isso propicia a mu- dança, com a chegada do outro e a manutenção do status quo, com a estratificação da carreira, ficando no topo da hierarquia um grupo homólogo àquele que deslanchou o profissionalismo há mais de um século. Nesse sentido, o contexto atual é favorável à pluralização da composição dos escritórios de advocacia, não só em relação às mulheres, mas às diferenças de forma geral. A divisão da carreira em sócios e associados permite a incorporação subalternizada dos novos ingressantes, mas ela não ocorre sem resistência e sem luta para mudar tal condição.

\title{
Referências
}

ADORNO, S. Os aprendizes do poder. Rio de Janeiro: Paz e Terra, 1988.

BARBALHO, R. A feminização das carreiras jurídicas e seus reflexos no profissionalismo. Tese (Doutorado em Sociologia). UFSCar, São Carlos, 2008.

BONELLI, M. G. Profissionalismo e política no mundo do direito. São Paulo, Fapesp/EdUFSCar/Sumaré, 2002.

BONELLI, M. G. Arlie Russell Hochschild e a sociologia da emoções. Cadernos Pagu 22, 2004.

BONELli, M. G; CUNHA, L. G.; OLIVEIRA, F. L.; BARBOZA, M. N. S. Profissionalização de advogados e advogadas na advocacia paulista. Tempo Social, v. 20, n.1, 2008.

BRUSCHINI, C.; LOMBARDI, M. R. A bi-polaridade do trabalho feminino no Brasil: O emprego doméstico e as 'novas ocupações. Cadernos de Pesquisa da Fundação Carlos Chagas, v. 1, n. 110, p. 67-1004, 2000.

COELHO, E. C. As Profissões Imperiais - Medicina, Engenharia e Advocacia no Rio de Janeiro 1822-1930. Editora Record, 1999.

FEUVRE, N.; LAPEYERE N. Les 'Scripts sexues' de carrière dans les professions juridiques en France. Knowledge, Work \& Society, v. 3, n. 1. Savoir, Travail et Société, p. 103-125, 2005.

FREIDSON, E. Professionalism: the third logic. Oxford: Polity Press, 2001.

HOCHSCHILD, A.R. The commercialization of intimate life: notes from home and work. Berkeley, The University of California Press, 2001.

JUNQUEIRA, E. B. A profissionalização da mulher na advocacia. Relatório Final: pesquisa financiada pela Fundação Carlos Chagas. Rio de Janeiro, 1999.

PERROT, M. As mulheres e os silêncios da História. Tradução de Viviane Ribeiro. Bauru (SP): Edusc, 2005.

PISCITELLI, Adriana. "Re-criando a (categoria) mulher?". In: ALGRANTI, Leila Mezan (Org.). A prática feminista e o conceito de gênero. Campinas, Unicamp, Coleção Textos Didáticos, n. 48, p.7-42, 2002.

SCHULTZ, U.; SHAW,G. (Ed.). Women in the world's legal professions. Hart Publishing. Oxford, Portland: Oregon, 2003.

SCOTT, J. A invisibilidade da experiência. Revista do Programa de Estudos Pós-Graduados em História, PUC, Proj. História, São Paulo, v. 16, p.297-325, 1998.

THORNTON, M. Dissonance and distrust: women in the legal profession. Melbourne. Oxford University Press, 1996.

\section{Professionalism and the Construction of Gender in Sao Paulo Law Firms}

\begin{abstract}
This article focuses on the social construction of gender in the legal career, in which predominates the logic of professionalism. It is based on both a quantitative survey about law firm teams in the city of Sao Paulo and qualitative interviews with 16 female and male lawyers working in the state of Sao Paulo, both from the capital and the countryside. The argument states that the ideology of professionalism is part of the gender building process in the legal practice, nourishing the female and male distinctions among the law firms, instead of overcoming such inequalities by increasing the professionalization of female lawyers. The fieldwork shows how this process is legitimized by both men and women in the legal career. However, the way in which gender building is put into practice varies according to the lawyer's rank in the career path, social origin, gender, and professionalization.
\end{abstract}

Key words: public policies; law firms; social participation; gender.

Data de recebimento do artigo: 30-05-2008

Data de aprovação do artigo: 05-09-2008 